\title{
DOPPLER ULTRASONOGRAPHY OF THE CENTRAL RETINAL ARTERY IN NORMALS TREATED WITH TOPICAL TIMOLOL
}

\author{
R. D. STEIGERWALT JR. ${ }^{1,2}$, G. BELCARO ${ }^{1,3}$, M. R. CESARONE ${ }^{1}$, G. LAURORA ${ }^{1}$, M. T. DE SANCTIS ${ }^{1}$ \\ and M. MILAZZO ${ }^{4}$ \\ Pescara, Rome and Catania, Italy, and London
}

\begin{abstract}
SUMMARY
Using high-resolution Duplex scanning it is possible to evaluate the blood flow velocity in the central retinal artery of eyes of normal individuals. The flow velocity can be divided into its systolic and diastolic phases. Topical timolol maleate $0.5 \%$, a non-selective beta-adrenergic receptor blocking agent, was then administered to one eye in each of the normals and the flow velocity was again recorded. The flow velocity improvement was significant, with a $43.58 \%$ increase in the systolic phase and a $61.53 \%$ increase in the diastolic phase. The diastolic component increased from $49.29 \%$ to $55.56 \%$. The increased flow velocity may be due to a vasodilatory effect of timolol. The technique is briefly described and the significance of the results discussed.
\end{abstract}

Timolol maleate is a widely used topical medication for lowering the intraocular pressure (IOP) in patients with glaucoma. ${ }^{1-5}$ It is a non-selective beta-adrenergic receptor blocking agent, the hypotensive effect of which has been extensively studied and found to be via a decrease in the rate of aqueous humour formation by the ciliary body ${ }^{6}$ Less information is available about the effect of topical timolol on the retinal circulation. Studies on the retinal circulation in rabbits as influenced by topical timolol were conducted by Watanabe et al. ${ }^{7}$ and Jay et al. ${ }^{8}$ using a radioactive microsphere technique. In phakic rabbits no significant change was found in the retinal blood flow, ${ }^{7}$ but in aphakic rabbits there was a significant increase in the blood flow in the retina and the optic nerve after topical imolol. ${ }^{8}$ Grunwald studied the effect of topical timolol maleate $0.5 \%$ on the retinal circulation in normal volunteers using bidirectional laser Doppler velocimetry and

From: 'Angiology and Vascular Surgery Centre, Hypertension Section, Pierangeli Clinic, Pescara, Italy; ${ }^{2}$ ARS Medical Clinic, Rome, Italy; ${ }^{3}$ Irvine Cardiovascular Laboratory for Investigation and Research, Academy Surgical Unit, St Mary's Hospital Medical School, London, UK; ${ }^{4}$ Mediterranean Microsurgery Centre, Sant Agata Li Battiati, Catania, Italy.

Correspondence to: Robert D Steigerwalt Jr, MD, Casa di Cura Pierangeli, Piazza L. Pierangeli 1, 65100 Pescara, Italy. monochromatic fundus photography. He found a significant increase in the flow velocity in the superior or inferior temporal retinal vein after topical timolol. ${ }^{9} \mathrm{He}$ obtained similar results in humans with ocular hypertension. ${ }^{10} \mathrm{His}$ technique requires direct visualisation of the vessels to be studied and therefore pupillary dilatation.

The search for an easy, safe and reliable means of evaluating the effect of topical timolol on the retinal circulation in humans without the necessity of pupillary dilatation and with minimal discomfort to the patient, led us to utilise the Duplex scanner. In 1988 Duplex scanning was introduced by one of us (G.B.) for studying the blood flow velocity in the central retinal artery (CRA) and vein $(\mathrm{CRV})^{11}$ and by Canning for studying the ophthalmic artery. ${ }^{12}$ In 1989 we used the ATL Ultramark 5 Duplex scanner to study the flow velocity in the CRA of normal subjects and of patients with diabetes and peripheral vascular disease. When we treated these patients with topical timolol $0.5 \%$ and repeated the flow velocity measurements there was an increase in the flow velocity in the CRA, but the number of patients was too small to make our results significant. ${ }^{13}$ In the present study we have expanded the number of normal eyes studied to 22 and our results are now significant. More recently the Duplex scanner and/or the Quantum angiodynographer have been used to study flow velocity in the eye, ${ }^{14-18}$ orbit $^{19-21}$ and cavernous sinus. ${ }^{22}$

The application of the Doppler phenomenon to the study of blood flow in the eye is relatively recent. At first the Doppler shift of laser light waves was used to study the circulation in branch retinal vessels. , $^{9,23-25}$ Bidirectional laser Doppler velocimetry can be done on, for example, branch retinal vessels, but this technique requires direct visualisation of the vessel being studied and pupillary dilatation as stated above. More recently the Doppler shift of ultrasound waves has been combined with grey-scale technology to give Duplex scanning. The Duplex scanner allows simultaneous B-mode imaging and Doppler evaluation to be performed. Direct visualisation of the fundus 
is not necessary and the examination can be performed through a closed eyelid. The presence of a cataract or vitreous haemorrhage does not interfere with the examination. When the two-dimensional flow information is encoded in colour and superimposed on the grey-scale image of the structure being studied it is called colour Doppler imaging or angiodynography. The Quantum angiodynographer is an example of this. The colour images of blood flow are encoded in red or blue depending on the direction of the flow in relation to the transducer (access probe). By convention flow towards the transducer is red and flow away is blue. The use of colour facilitates the localisation of the vessels being studied but the measurements of the flow velocity are the same with either the Quantum or the Duplex scanner.

The purpose of this study was to evaluate the effect of a topical non-selective beta-adrenergic receptor blocking agent, in particular timolol maleate, on retinal blood flow. Beta-adrenergic receptor blocking agents are known in general for their vasoconstrictive effects, and cause a reduction in blood flow velocity to most tissues except the brain. ${ }^{26}$ The abovementioned studies on the eye suggested an increase not a decrease in the flow velocity in the retina with the use of topical timolol $0.5 \% .^{7-10,13}$ We have used Duplex scanning to evaluate this problem.

\section{MATERIALS AND METHODS}

The high-resolution ATL Ultramark 4 Duplex scanner (Advanced Technology Laboratories, Bothell, Washington, USA) with the variable focus $5,7.5,10 \mathrm{MHz}$ access probe with remote control was used. A nominal imaging frequency of $10 \mathrm{MHz}$, a transmitted Doppler frequency of $5 \mathrm{MHz}$ and a wall filter setting of $200 \mathrm{~Hz}$ were used in each measurement. The gain was set between $50 \%$ and $60 \%$, the reject at 0 , the power at $50 \%$ and the maximum velocity at 1.77 .

The patient lay on his or her back on the examining table with a pillow under the head for comfort. The examiner sat at the head of the bed. With the patient resting supine, the eyes were closed and an acoustic gel applied externally to the skin of the eyelid. The access probe was held in the examiner's hand and placed perpendicularly on the closed eyelid. Ideally the angle of incidence of the probe and the CRA should be as close to zero as possible. Only gentle contact is needed to evaluate the flow. The hypoacoustic image of the optic nerve was visualised and the sample volume placed onto the ultrasonic retinal surface. The retinal flow velocity was recorded continuously for 30 seconds and an average of 10 waveforms used to calculate the results. The flow velocity of the CRA was measured in centimetres per second; the systolic phase was reported as peak systolic flow velocity (PSFV) and the diastolic phase as peak diastolic flow velocity (PDFV).

The 22 subjects in the present investigation were all healthy white volunteers. There was no history of ocular or systemic pathology and all had normal eye examinations with a best corrected visual acuity of $20 / 20$ or better. The IOP was $21 \mathrm{mmHg}$ or less and the anterior segment and fundus examinations were normal. None were known diabetics, none had known circulatory problems and none were taking systemic medication. The pupils of the eyes were not dilated during the flow measurements. Informed consent was obtained after the experiment had been fully explained.

One eye was selected from each of the volunteers and the PSFV and the PDFV of the CRA as it exits from the optic nerve head were measured. The carotid blood flow was also recorded on the same side as the eye selected to be studied, to ensure that haemodynamically significant lesions were not present that could alter the ocular measurements. A drop of timolol $0.5 \%$ was instilled in the eye followed by a second drop 5 minutes later. After 30-45 minutes the PSFV and the PDFV in the CRA were again measured and recorded. The diastolic component [D.Comp. $=\mathrm{PDFV} /(\mathrm{PSFV} / 100)]$ was calculated for the flow velocity before and after topical timolol.

\section{RESULTS}

The 22 normal subjects had a mean age of 32.7 years (range 23-47 years). Table I lists the subjects in order of increasing age. The mean brachial systolic pressure was $124.4 \mathrm{mmHg}$ and the mean brachial diastolic pressure was $80.6 \mathrm{mmHg}$. The PSFV and the PDFV of the CRA were measured before and after topical timolol are also reported in Table I. The flow increased in all the eyes. The mean PSFV in the CRA significantly increased from $19.09 \mathrm{~cm} / \mathrm{s}$ (SD 3.21) to $27.41 \mathrm{~cm} / \mathrm{s}$ (SD 4.33) $(p<0.001 ; t$ value 10.27) (Table II). This was an increase of $43.58 \%$. The mean PDFV increased from $9.41 \mathrm{~cm} / \mathrm{s}$ (SD 2.63) to $15.2 \mathrm{~cm} / \mathrm{s}$ (SD 3.29) $(p<0.001 ; t$ value 13.09). This was an increase of $61.53 \%$. Furthermore there was an increase in the D.Comp. from $49.29 \%$ before timolol to $55.56 \%$ after timolol (Table II).

Table I. Flow velocity measurements $(\mathrm{cm} / \mathrm{s})$ before and after two drops of timolol $0.5 \%$ in 22 normal subjects listed by increasing age

\begin{tabular}{|c|c|c|c|c|}
\hline \multirow{2}{*}{$\begin{array}{l}\text { Age } \\
(\mathrm{yr})\end{array}$} & \multicolumn{2}{|c|}{ Before timolol } & \multicolumn{2}{|c|}{ After timolol } \\
\hline & PSFV & PDFV & PSFV & PDFV \\
\hline 23 & 19 & 10 & 28 & 16 \\
\hline 23 & 17 & 5 & 23 & 10 \\
\hline 24 & 18 & 8 & 21 & 11 \\
\hline 25 & 18 & 10 & 31 & 17 \\
\hline 27 & 20 & 12 & 33 & 18 \\
\hline 28 & 23 & 10 & 28 & 16 \\
\hline 28 & 18 & 6 & 22 & 10 \\
\hline 30 & 18 & 8 & 28 & 17 \\
\hline 30 & 19 & 10 & 33 & 18 \\
\hline 31 & 21 & 13 & 28 & 16 \\
\hline 33 & 28 & 10 & 28 & 14 \\
\hline 33 & 19 & 11 & 33 & 21 \\
\hline 33 & 12 & 4 & 20 & 9 \\
\hline 33 & 15 & 5 & 20 & 13 \\
\hline 34 & 22 & 9 & 30 & 13 \\
\hline 35 & 15 & 10 & 24 & 18 \\
\hline 36 & 21 & 12 & 32 & 19 \\
\hline 38 & 20 & 10 & 29 & 16 \\
\hline 38 & 19 & 14 & 32 & 18 \\
\hline 44 & 22 & 12 & 29 & 18 \\
\hline 46 & 18 & 10 & 23 & 12 \\
\hline 47 & 18 & 8 & 28 & 15 \\
\hline
\end{tabular}

PSFV, peak systolic flow velocity; PDFV, peak diastolic flow velocity. 
Table II. Variation of blood flow velocity $(\mathrm{cm} / \mathrm{s})$ after two drops of timolol $0.5 \%$ in 22 normal subjects

\begin{tabular}{lccrrrr}
\hline & \multicolumn{2}{c}{ PSFV } & & \multicolumn{2}{c}{ PDFV } & \\
\cline { 2 - 3 } & Mean & SD & & Mean & SD & D.Comp. \\
\hline Before timolol & 19.09 & 3.21 & & 9.41 & 2.63 & $49.29 \%$ \\
After timolol & 27.41 & 4.33 & & 15.20 & 3.29 & $55.56 \%$ \\
Percentage increase & 43.58 & & 61.53 & & \\
\hline
\end{tabular}

PSFV, peak systolic flow velocity; PDFV, peak diastolic flow velocity; D.Comp., diastolic component $=$ PDFV/(PSFV/100).

\section{DISCUSSION}

Most of the arteries in the body have sympathetic innervation which controls the blood circulation. In the case of the eye histochemical studies on human and animal tissue have shown the absence of adrenergic innervation to the retinal vessels. The only exception is the rabbit eye. As regards the CRA the adrenergic and cholinergic nerve fibres accompany it only to the level of the lamina cribrosa and do not appear to pass into the human retina. ${ }^{27,28}$ The retinal arterioles appear to be without innervation and therefore it is thought that autoregulation controls the retinal circulation. Autoregulation is a general phenomenon of the microcirculation in which the blood flow is regulated by local conditions. It can be divided into two mechanisms: an increase in the tone of the smooth muscle in response to an increased intraluminal pressure (myogenic mechanism) and a response of the smooth muscle tone of the vessel to local metabolic needs (metabolic mechanism). Oxygen tension, carbon dioxide tension, $\mathrm{pH}$ and lactate may be the mediators. ${ }^{29,30}$ Although the retina utilises autoregulation and lacks sympathetic innervation there is evidence that other factors may play a role in the regulation of its blood flow. Recent studies have shown that binding sites are present on retinal blood vessels for alphaand beta-adrenergic agents, cholinergic agents and angiotensin. ${ }^{31-36}$ In the future it may be found that some of these binding sites play a role in the chemical mediation of retinal circulation.

The purpose of this study was to evaluate the effect of a topical non-selective beta-adrenergic receptor blocking agent, timolol maleate, on the retinal blood flow velocity. As stated before beta-adrenergic receptor blocking agents are known in general for their vasoconstrictive effects that produce a reduction in blood flow to most tissues, the brain being an exception. ${ }^{26}$ The results of this study showed a significant increase, not a decrease, in the arterial blood flow velocity in the retina with the use of topical timolol $0.5 \%$. The reason for this increase in ocular flow velocity with a topical beta-adrenergic receptor blocking agent is not yet known and further study will be necessary to clarify the mechanism. At the retinal vascular level the lack of sympathetic innervation and the presence of some binding sites may be important. The increased flow velocity in the artery may be explained by a vasodilatory effect of the drug on the retinal vessels. There was an increase in the D.Comp. from $49.29 \%$ before timolol to $55.56 \%$ after timolol. The D.Comp. is a measure- ment of the peripheral vascular resistance, an increase indicating a decrease in the peripheral vascular resistance. In the eye the increase in D.Comp. means a decrease in the peripheral vascular resistance which may have led to the subsequent increase in flow velocity. There is also other evidence of a vasodilatory mechanism. A recent study investigating the contractile responses of bovine retinal microarteries in vitro found a relaxation of the vessel walls to calcium-antagonists and beta-antagonists including timolol and propranolol. ${ }^{37}$ This is further evidence that the increased flow velocity caused by timolol in the retina may be due to a vasodilatory effect. It must be remembered that timolol does lower the IOP pressure and the relevance of this to the increased blood flow velocity remains to be determined. It will be necessary to evaluate any changes in the flow velocity of the CRA when using other glaucomatous medications that lower the IOP but which are not beta-adrenergic receptor blocking agents. By comparing the results obtained from these medications with those obtained from timolol it will be possible to evaluate the effect of a decrease in IOP on the ocular flow velocity.

There are noticeable differences between our results and those obtained by Grunwald who also measured the ocular blood flow response to topical timolol. He found an $11 \%$ increase in the flow velocity in branch temporal veins and a $13 \%$ increase in the volumetric flow in the same vessels in the eyes of normals. ${ }^{9}$ In the eyes of ocular hypertensives there was a $12 \%$ increase in the venous flow velocity and an $8.4 \%$ increase in the volumetric venous flow. ${ }^{10}$ We found an increase in the flow velocity of $43.58 \%$ in the systolic phase and a $61.53 \%$ increase in the diastolic phase in the CRA - much larger values than those reported by Grunwald. There are several differences between our study and those of Grunwald which may explain this apparent discrepancy. We were measuring arterial blood flow of the CRA at the level of the optic nerve head while Grunwald was measuring venous flow in branch vessels. Our measurements were taken at 30-45 minutes after the second drop of timolol while those of Grunwald were at 90-120 minutes. This time difference may be important. We were using the Duplex scanner while Grunwald was using the laser Doppler. The instruments are different enough that it is difficult to compare the results obtained from each of them. We measured the carotid blood flow velocity in all of our volunteers to exclude patients with haemodynamically significant lesions. Carotid lesions can alter the flow velocity enough that the flow in the CRA will also be different. For this reason we excluded anyone with these lesions. This was no done by Grunwald. We did not measure vessel diameters in order to calculate the volumetric flow as did Grunwald because the Duplex scanner and Quantum are not designed for these measurements. Because of the abovementioned differences, comparisons between the studies are difficult.

As more information becomes available about the effect of topical timolol on the retinal circulation we may need to consider situations in which the medicine may be 
benefical or detrimental to the retinal and/or optic nerve head circulations. Conditions in which retinal ischaemia is present may benefit from the medication. The effect of increased flow on retinal oedema will also need to be evaluated. The same considerations may need to be taken into account when using systemic medications which are known to be vasodilators. In 1989 we evaluated the effect of systemic vasodilators, calcium-antagonists, on the flow velocity of the CRA. We reported our results in patients with peripheral and/or central vascular disease who had a reduction in retinal flow velocity. Treatment with either nifedipine or nimodipine given orally led to an increased flow velocity. ${ }^{13}$ These and other situations will need to be evaluated in the future as our understanding of the retinal circulation improves.

The authors wish to thank Professor Paolo Palazzi, University of Rome, for his help with the statistics and the volunteers from St Mary's Hospital Medical School and the Pierangeli Clinic without whom the study would not have been possible. This study was supported by funds from ESSO Italia and the authors of the article.

Key words: Central retinal artery, Doppler ultrasonography, Duplex scanner, Quantum angiodynographer, Timolol maleate.

\section{REFERENCES}

1. Katz IM, Hubbard WA, Getson AJ, Gould AL. Intraocular pressure decrease in normal volunteers following timolol ophthalmic solution. Invest Ophthalmol Vis Sci 1976;15:489.

2. Zimmerman TJ, Kaufman HE. Timolol, a beta-adrenergic blocking agent for the treatment of glaucoma. Arch Ophthalmol 1977;95:601.

3. Zimmermann TJ, Kaufman HE. Timolol: dose response and duration of action. Arch Ophthalmol 1977;95:605.

4. Radius R, Diamond G, Pollak I, Langham ME. Timolol: a new drug for the management of chronic simple glaucoma. Arch Ophthalmol 1978;96:1003.

5. Wilson RP, Kanal N, Spaeth GL. Timolol: its effectiveness in different types of glaucoma. Ophthalmology 1979;86:43.

6. Coakes RL, Brubaker RF. The mechanism of timolol in lowering intraocular pressure. Arch Ophthalmol 1978;96:2045.

7. Watanabe K, Chiou GC. Action mechanism of timolol to lower the intraocular pressure in rabbits. Ophthalmic Res $1983 ; 15: 160$.

8. Jay WM, Aziz MZ, Green K. Effect of topical epinephrine and timolol on ocular and optic nerve blood flow in phakic and aphakic rabbit eyes. Curr Eye Res 1984;3:1199.

9. Grunwald JE. Effect of topical timolol on the human retinal circulation. Invest Ophthalmol Vis Sci 1986;27:1713.

10. Grunwald JE. Effect of timolol maleate on the retinal circulation of human eyes with ocular hypertension. Invest Ophthalmol Vis Sci 1990;31:521.

11. Belcaro G, Marelli C. Evaluation of blood flow in the central retinal artery and vein by Duplex scanning in patients with sudden loss of vision. Acta Chir Scand (Suppl) 1988;546:52.

12. Canning CR, Restori M. Doppler ultrasound studies of the ophthalmic artery. Eye 1988;2:92.

13. Belcaro G, Steigerwalt RD Jr, Laurora G, Cesarone MR. Valutazione del flusso nella arteria e nella vena centrale della retina con Duplex scanning ad alta risoluzione. Minerva Angiol 1989;14:175.

14. Belcaro G, Steigerwalt RD. Defibrotide treatment in central retinal vein thrombosis: evaluation by high resolution Duplex scanning [abstract]. In: Forum on angiology of the Royal Society of Medicine, London.

15. Guthoff RF, Berger RW, Winkler P, Helmke K, Chumbley
LC. Doppler ultrasonography of the ophthalmic and central retinal vessels. Arch Ophthalmol 1991;109:532.

16. Michelson G, Gierth K, Priem R, Laumer R. Gepulste Dopplersonographie der arteria ophthalmica bei Retinopathia diabetica proliferans. Fortschr Ophthalmol 1990;84:551.

17. Guthoff RF, Berger RW, Winkler P, Helmke K, Chumbley LC. Doppler ultrasonography of malignant melanomas of the uvea. Arch Ophthalmol 1991;109:537.

18. Berger RW, Guthoff R, Helmke K, Winkler P, Draeger J. Doppler sonographische Befunde der arteria und vena centralis retinae. Fortschr Ophthalmol 1989;86:334.

19. Lieb WE, Cohen SM, Merton DA, Shields JA, Mitchell DG, Goldberg BB. Color Doppler imaging of the eye and orbit. Arch Ophthalmol 1991;109:527.

20. Lieb WE, Merton DA, Shields JA, Cohen SM, Mitchell DG, Goldberg BB. Color Doppler imaging in the demonstration of an orbital varix. Br J Ophthalmol 1990;74:305.

21. Erickson SJ, Hendrix LE, Massaro BM, et al. Color Doppler flow imaging of the normal and abnormal orbit. Radiology 1989;173:511.

22. Flaharty PM, Lieb WE, Sergott RC, Bosley TM, Savino PJ. Color Doppler imaging: a new noninvasive technique to diagnose and monitor carotid cavernous sinus fistulas. Arch Ophthalmol 1991;109:522.

23. Riva CE, Grunwald JE, Sinclair SH, Petrig BL. Blood velocity and volumetric flow rate in human retinal vessels. Invest Ophthalmol Vis Sci 1985;26:1124.

24. Grunwald JE, Riva CE, Sinclair SH, Brucker AJ, Petrig BL. Laser Doppler velocimetry study of retinal circulation in diabetes mellitus. Arch Ophthalmol 1986;104:991.

25. Feke G, Tagawa H, Deupree DM, Goger DG, Sebag J, Weiter JJ. Blood flow in the normal human retina. Invest Ophthalmol Vis Sci 1989;30:58.

26. Nies AS, Evans GH, Shand DG. Regional hemodynamic effects of beta-adrenergic blockade with propranolol in the unanesthetized primate. Am Heart J 1973;85:97.

27. Laties AM. Central retinal artery innervation: absence of adrenergic innervation to the intraocular branches. Arch Ophthalmol 1967;77:405.

28. Ye X, Laties AM, Stone RA. Peptidergic innervation of the retinal vasculature and optic nerve head. Invest Ophthalmol Vis Sci 1990;31:1731.

29. Anderson DR. Anatomy and physiology of ocular blood flow. In: Lambrou GN, Greve EL, editors. Ocular blood flow in glaucoma. Amsterdam: Kugler and Ghedini, 1989:55-9.

30. Riva EC, Grunwald JE, Sinclair SH. Laser Doppler velocimetry study of the effect of pure oxygen breathing on retinal blood flow. Invest Ophthalmol Vis Sci 1983;24:47.

31. Rockwood EJ, Fantes F, Davis EB, Anderson DR. The response of retinal vasculature to angiotensin. Invest Ophthalmol Vis Sci 1987;28:676.

32. Forster BA, Ferrari-Dileo G, Anderson DR. Adrenergic alpha-1 and alpha- 2 binding sites are present in bovine retinal blood vessels. Invest Ophthalmol Vis Sci 1987;28:1741.

33. Ferrari-Dileo G, Davis EB, Anderson DR. Angiotensin binding sites in bovine and human retinal blood vessels. Invest Ophthalmol Vis Sci 1987;28:1747.

34. Ferrari-Dileo G, Ryan JW, Rockwood EJ, Davis EB, Anderson DR. Angiotensin-converting enzyme in bovine, feline and human ocular tissues. Invest Ophthalmol Vis Sci 1988; 29:876.

35. Ferrari-Dileo G. Beta- 1 and beta- 2 adrenergic binding sites in bovine retina and retinal blood vessels. Invest Ophthalmol Vis Sci 1988;29:695.

36. Ferrari-Dileo G, Davis EB, Anderson DR. Biochemical evidence for cholinergic activity in retinal blood vessels. Invest Ophthalmol Vis Sci 1989;30:473.

37. Hoste AM, Boels PJ, Andries LJ, Brutsaert DL, De Laey JJ. Effects of beta-antagonists on contraction of bovine retinal microarteries in vitro. Invest Ophthalmol Vis Sci 1990;31: 1231. 